\title{
Protection from DNA Damage by Use of an Aronia Food Supplement-Results from a Pilot Human Intervention Study
}

\author{
Tamara Bakuradze $^{1} \cdot$ Daniela Becker ${ }^{1} \cdot$ Julia Reischmann $^{1} \cdot$ Peter Meiser $^{2} \cdot$ Jens $_{\text {Galan }}{ }^{3} \cdot$ Elke Richling $^{1}$ (D)
}

Published online: 6 April 2019

(C) The Author(s) 2019

\begin{abstract}
Purpose of Review Polyphenols from fruits and other plant sources exhibit protective effects against DNA damage and markers of oxidative stress. Meanwhile, previous investigations tested rather large volumes of polyphenol-rich fruit juices; hence, there is a lack of information on the efficacy of small-volume supplementation concepts suitable for daily routine. We designed a 6-week pilot study on the use of such a food supplement (aronia+) including ten healthy male volunteers and tested for effects on DNA integrity, oxidation-related parameters (Nrf2, SOD, GPx, CAT, and oxidized LDL), and blood lipids.

Recent Findings Tendencies towards a decrease were observed for both total and background DNA strand breaks but were not significant after 4-week consumption of the food supplement. Transcription levels of Nrf2 were elevated; meanwhile, Nrf2/ARErelated enzymes were not affected (GPx) or even slightly decreased (SOD, CAT). Marginal reduction was observed for total and LDL cholesterol, whereas other parameters remained almost unchanged.

Summary This explorative study yields first indications on protective effects on DNA damage after intake of even small volumes of polyphenol-rich food supplements. These observations must be confirmed in a follow-up study with a higher number of included volunteers and an integration of a control group in order to clearly assess the effect of the intervention.
\end{abstract}

Keywords Aronia $\cdot$ Antioxidants $\cdot \mathrm{Nrf2} \cdot$ DNA strand breaks $\cdot$ Comet assay

$\begin{array}{ll}\text { Abbreviations } \\ \text { BIA } & \text { Bioelectrical impedance analyzer } \\ \text { BS } & \text { Blood sampling } \\ \text { CAT } & \text { Catalase } \\ \text { GPx } & \text { Glutathione peroxidase } \\ \text { HDL } & \text { High-density lipoproteins } \\ \text { LDL } & \text { Low-density lipoproteins } \\ \text { Nrf2 } & \text { Nuclear factor erythroid 2 (NFE2)-related factor } 2\end{array}$

This article is part of the Topical Collection on Redox Modulators

Electronic supplementary material The online version of this article (https://doi.org/10.1007/s40495-019-00178-5) contains supplementary material, which is available to authorized users.

Elke Richling

richling@chemie.uni-kl.de

1 Food Chemistry \& Toxicology, Department of Chemistry, Technische Universitaet Kaiserslautern, Erwin-Schroedinger-Straße 52, 67663 Kaiserslautern, Germany

2 Ursapharm Arzneimittel GmbH, Saarbruecken, Germany

3 Gruenstadt, Germany
TC Total cholesterol

TG Triglycerides

\section{Introduction}

Increased release and inefficient detoxification of reactive oxygen species have been linked to the pathogenesis of a variety of chronic and life-threatening diseases, such as diabetes mellitus type 2 and cancer, as well as neurodegenerative and cardiovascular diseases [1,2]. Oxygen radicals mediate damage to cellular components such as lipids, enzymes, and even genetic information via either direct or indirect mechanisms. Antioxidants on the other hand protect the organism from damage by neutralizing free radicals, by inactivation of redox-active transition metals, through modulation of redox-sensitive signal cascades, and by subsequent induction of antioxidative enzymes such as catalase (CAT), superoxide dismutase (SOD), and glutathione peroxidase (GPx) [3].

Many therapeutic and preventive approaches have been proposed; however, only few cleared the hurdle from preclinical towards clinical investigations. Moreover, some 
interventions even proved to be rather non-beneficial or even harmful. This holds in particular true for studies investigating high vitamin dosages and long-term interventions [4-6]. Therefore, moderate supplementation concepts integrating naturally occurring mixtures of antioxidants might resemble a more promising approach. Consumption of an anthocyanin-rich red fruit juice over a period of 4 weeks indeed led to a decrease in oxidative DNA damage and to an increase of the glutathione level in human subjects as compared with a control group. The daily intake, $700 \mathrm{~mL}$ of the red fruit juice, yet cannot be considered suitable for daily routine [7]. Similarly, consumption of an anthocyanin-rich bilberry pomace extract led to a decrease in background and total DNA strand breaks already within $2 \mathrm{~h}$ after application [8]. Again, the applied dosage of $10 \mathrm{~g}$ bilberry extract corresponding to $2.5 \mathrm{~g}$ of purified anthocyanin is far beyond usual daily intake quantities [9].

Aronia (Aronia melanocarpa) is an edible berry originating from Northern America [10]. Freshly pressed juice from these fruits is high in vitamin C $(200 \mathrm{mg} / \mathrm{L})$ and sorbitol $(80 \mathrm{~g} / \mathrm{L})$ but low in monosaccharides such as fructose and glucose. The total content of phenolic compounds is reported to be $7.8 \mathrm{~g} /$ $100 \mathrm{~g}$ dry weight [11]. Aronia fruits and products thereof are reported to possess antioxidant, cardioprotective, hepatoprotective, antimutagenic, and antidiabetic properties (summarized by [10]).

Another preventive approach aims at the inhibition of intracellularly released reactive oxygen species by ensuring a regular and sufficient intake of cofactors of endogenous enzymes such as zinc and selenium. Apart from being a structural component of superoxide dismutase, which converts superoxide species to oxygen and hydrogen peroxide, zinc also functions as an antioxidant by binding to thiols from cellular proteins, thereby protecting these structures from oxidation, and by displacement of redox-active metals such as iron and copper from lipids and proteins which reduces the production of hydroxyl radicals. Zinc furthermore induces the expression of metallothioneins, proteins acting as scavengers of free radicals and for detoxification of non-essential metals, and contributes to intracellular homeostasis of reduced glutathione $[12,13]$.

Selenium incorporates into proteins bearing selenocysteine residues instead of the sulfur-containing cysteine [14, 15]. Selenium-dependent glutathione peroxidase metabolizes hydrogen peroxide (and therefore constitutes a successor enzyme to the above mentioned superoxide dismutase, besides catalase) and more complex products of lipid peroxidation. The function of another enzyme, thioredoxin reductase, is well described - thioredoxin reductase plays an essential role in the regulation of the cellular redox status - meanwhile, the physiological role of numerous other selenium-containing enzymes remains to be elucidated [16-18].
Taking both approaches together, thus, a formulation containing an anthocyanin-rich fruit juice in an amount suitable for use in daily routine in combination with the trace elements zinc and selenium might be an appropriate practice in order to support the body's antioxidative defense. In a recent in vitro study, synergistic effects of a mixture of aronia juice concentrate and sodium selenite were observed regarding the inhibition of inflammatory parameters (TNF- $\alpha$, IL-6, IL-8, and $\mathrm{PGE}_{2}$ ) and the NF-KB pathway [19].

In this explorative human intervention study including ten male volunteers, we therefore set out to monitor the effects of such a nutritional supplement, namely aronia+, for 4 weeks on parameters of oxidative stress such as DNA strand breaks, Nrf2 transcription, and activities of SOD, CAT, or GPx in the blood samples collected. Additionally, the levels of oxidized LDL and blood lipids were determined in blood.

\section{Materials and Methods}

\section{Investigational Product}

The food supplement aronia+ was supplied by Ursapharm Arzneimittel GmbH, Saarbruecken, Germany. aronia+ contains aronia juice (from concentrate), sucrose, citric acid, sodium benzoate, potassium sorbate, zinc gluconate, natural aroma, niacin, pantothenic acid, vitamin B1, vitamin B2, vitamin B6, sodium selenite, and vitamin D. The aronia juice concentrate used in aronia+ was previously analyzed in detail [19].

\section{Study Design}

The human intervention study was performed from January 18 to March 1, 2017. The study was approved by the ethics committee Rhineland-Palatinate, Mainz, Germany (no. 837.013.14 (9252-F)). Male, healthy, non-smoking volunteers were recruited within this period. After an informative meeting, the volunteers had at least $24 \mathrm{~h}$ to decide on their participation. After that, written consent forms were signed and obtained from all volunteers. Exclusion criteria included smoking, obesity or underweight (BMI $<19$ or $>32 \mathrm{~kg} / \mathrm{m}^{2}$ ), use of medication, participation at other studies, deviation of the nutritional requirements, practice of competitive sport, and chronic or inflammatory diseases. Inclusion criteria were the following: non-smokers, age 20 to 50 years, BMI between 19 and $32 \mathrm{~kg} / \mathrm{m}^{2}$, Caucasian origin, and persons accepting the nutritional requirements. All participants were asked to maintain their usual dietary habits for the duration of the study, except for the intake of food rich in polyphenols like coffee, chocolate, red wine, and tea. All volunteers were informed of the objectives of the study and consent was received for their participation. Before the study started, volunteers underwent a medical examination including weight, body height, blood pressure measurement, and standard 
clinical parameters, such as creatinine, $\gamma$-glutamyl transferase, and C-reactive protein, to ensure that they fulfill the state of health. After a polyphenol-reduced diet (no consumption of polyphenol-rich fruits and vegetables, fruit juice, red wine, beer, tea, chocolate, and vitamin/mineral preparations) of 14 days, the volunteers consumed two ampoules of aronia+ $(25 \mathrm{~mL}$ each) together with $200 \mathrm{~mL}$ water during the day (between 8 a.m. and 4 p.m., see supplementary material) for 4 weeks, being continuously adherent to the restricted diet. Volunteers were asked to shake the ampoule before pouring it out. For control of compliance, the daily intake of aronia+ was recorded (day and hour).

\section{Blood Samples}

Blood samples $(40 \mathrm{~mL})$ were taken the day after the wash-out period (before beginning of the aronia+ intake) and at the end of the study exactly 1 hour after the last aronia+ intake.

\section{Anthropometric Measurements}

Body height and weight of volunteers were measured using a digital scale Seca delta 707 (Seca, Hamburg, Germany), and BMI $\left(\mathrm{kg}\right.$ per $\left.\mathrm{m}^{2}\right)$ was calculated. For estimating the body composition (total body water (TBW), fat mass (FM), and fat-free mass (FFM)), a bioelectrical impedance analyzer 101 (BIA 101, SMT medical GmbH, Wuerzburg, Germany) was used. The measurements were performed in the morning of day 1 and day 29 with fasted subjects at horizontal position and emptied bladder. Special skin electrodes were placed at the right hand and foot on dry skin, following the manufacturer's instructions.

\section{DNA Strand Breaks}

DNA strand breaks in whole blood were determined by alkaline single-cell gel electrophoresis (comet assay) according to [20], with slight modifications as described previously [21]. The aliquots of whole blood $(6 \mu \mathrm{L})$ were mixed with $65 \mu \mathrm{L}$ low-melting agarose, applied onto a precoated microscope slide and put onto ice $\left(0{ }^{\circ} \mathrm{C}\right)$ to harden, and were afterwards submitted to lysis (overnight, $4{ }^{\circ} \mathrm{C}$ ). Thereafter, slides were washed three times in enzyme buffer and were drained and covered with $50 \mu \mathrm{L}$ of either enzyme buffer or formamidopyrimidine-DNA glycosylase (FPG enzyme) to differentiate between background and total DNA strand breaks (background strand breaks and oxidized bases). After DNA unwinding ( $\mathrm{pH}$ 13.5, $20 \mathrm{~min}, 4{ }^{\circ} \mathrm{C}$ ) and horizontal gel electrophoresis (20 min, $25 \mathrm{~V}, 300 \mathrm{~mA}$ ), slides were washed, stained with GelRed, and analyzed using a fluorescence microscope (Imager, A1, filter set 15, Zeiss, Germany) and computerized image analysis (Comet Assay IV, Perceptive
Instruments, Suffolk, GB), scoring $2 \times 50$ cells per slide. DNA migration was calculated as mean tail intensity (TI\%: DNA in the comet tail in percent of total DNA).

\section{Plasma Extraction}

To achieve plasma, each 9-mL EDTA monovette was centrifuged at room temperature for $10 \mathrm{~min}$ at $2000 \times \mathrm{g}$. The achieved plasma was separated into a $1.5-\mathrm{mL}$ reaction vial and stored at $-80^{\circ} \mathrm{C}$ until further processing of the sample (SOD, GPx, and CAT activities and oxidized low-density lipoprotein (oxLDL)).

\section{Isolation of Human Peripheral Blood Lymphocytes}

$4.5 \mathrm{~mL}$ of freshly collected human blood anticoagulated with EDTA was layered on $4.5 \mathrm{~mL}$ of Histopaque 1077 (Sigma, Steinheim, Germany). After Ficoll gradient centrifugation for $25 \mathrm{~min}\left(400 \times \mathrm{g}\right.$, without break, $\left.25^{\circ} \mathrm{C}\right)$, the lymphocytes were collected from the layer between the plasma and Histopaque 1077 phases (second layer) and were transferred into $10 \mathrm{~mL}$ of RPMI 1640 medium (Gibco, Life Technologies, Darmstadt, Germany) supplemented with $10 \%$ fetal calf serum (FCS) and $1 \%$ penicillin/streptomycin. Thereafter, the cell suspension was centrifuged for $10 \mathrm{~min}(250 \times \mathrm{g})$, and the pellet was resolved in $10 \%$ FCS medium and repeatedly centrifuged. Cells were transferred into $1 \mathrm{~mL}$ of RNAlater stabilization reagent (Qiagen, Hilden, Germany) and stored at $-80{ }^{\circ} \mathrm{C}$.

\section{RNA Extraction and RT-qPCR}

Total RNA from lymphocytes was isolated using the Qiagen RNeasy Mini Kit column extraction kit (Qiagen). Concentration and purity of total RNA were measured by the ratio of $\mathrm{A}_{260} / \mathrm{A}_{280}$ utilizing a NanoDrop system (Thermo Fisher Scientific, Dreieich, Germany), and thereafter, samples were directly reverse-transcribed to complementary DNA (cDNA) (QuantiTect Reverse Transcription Kit (Qiagen)) according to the manufacturer's instruction and stored at $20^{\circ} \mathrm{C}$. cDNA obtained from the RT reaction was subjected to RT-qPCR using the QuantiTect SYBR Green PCR kit (Qiagen) and the following specific primer sets (Eurofins MWG Operon, Ebersberg, Germany) for the target gene Nrf2 and the housekeeping genes GAPDH and $\beta$-actin:

actb forward 5'-CAATGTGGCCGAGGACTTT-3' actb_reverse 5'-AGTGGGGTGGCTTTTAGGATG-3'

GAPDH forward 5'-GTCAAGGCTGAGAACGGGAA-3'

GAPDH reverse 5'-TCGCCCCACTTGATTTTGGA-3'

Nrf2 forward 5'-TGTGGCATCACCAGAACACT-3'

Nrf2 reverse 5'-TTTGACACTTCCAGGGGCAC-3'

Primer concentrations used were according to the manufacturer's guidelines in the QuantiTect SYBR Green PCR kit (Qiagen). RT-qPCR was performed with CFX Connect Real- 
Time System (Bio-Rad). Cycling conditions were the following: a $95{ }^{\circ} \mathrm{C}$ initial TAQ polymerase activation for $15 \mathrm{~min}$ followed by 40 cycles of $94{ }^{\circ} \mathrm{C}$ denaturation $(15 \mathrm{~s}), 55^{\circ} \mathrm{C}$ annealing (30 s), and $72{ }^{\circ} \mathrm{C}$ extension (30 s) and a final dissociation stage to generate a melting curve for verification of amplification product specificity. Modification of Nrf2 gene expression normalized to the housekeeping genes (GAPDH and $\beta$-actin) and compared with the negative control (results obtained after the wash-out phase) was determined using the $2^{-\Delta \Delta C t}$ method.

\section{Blood Lipids}

Blood lipids such as high-density lipoproteins (HDL), lowdensity lipoproteins (LDL), total cholesterol (TC), and triglycerides (TG) were determined with standard methods in the laboratory of Westpfalz-Klinikum Kaiserslautern.

\section{Superoxide Dismutase Assay}

Superoxide dismutase (SOD) activity in plasma samples was determined with commercially available Superoxide Dismutase Assay Kit from Cayman Chemical (Biomol, Hamburg, Germany). Briefly, the test is a photometric microtiter test. Superoxide radical anions are generated by xanthine oxidase from hypoxanthine. The radicals react with watersoluble tetrazolium salt and form a yellow formazan determined at $450 \mathrm{~nm}$. SOD inhibits this reaction, and therefore, the SOD activity is proportional to the reduction in the formazan.

\section{Catalase Assay}

Catalase activity (CAT) was determined with Catalase Assay Kit from Cayman Chemical (Biomol, Hamburg, Germany). The test is a photometric microtiter test as well. Here, catalase transfers methanol in the presence of $\mathrm{H}_{2} \mathrm{O}_{2}$ into formaldehyde and water. Formaldehyde reacts with the chromogen purpald (4-amino-3-hydrazino-5-mercapto-1,2,4-triazole) to a heterocyclic compound which is oxidized with potassium periodate to a stable violet dye determined at $540 \mathrm{~nm}$.

\section{Glutathione Peroxidase Assay}

Glutathione peroxidase (GPx) activity was measured by Glutathione Peroxidase Assay Kit from Cayman Chemical (Biomol, Hamburg, Germany). This photometric assay determines the reaction of glutathione (GSH) to glutathione disulfide (GSSG) in the presence of hydroperoxides and glutathione peroxidase. Afterwards, GSSG is reduced in the presence of glutathione reductase to GSH. The oxidation of NADPH to $\mathrm{NADP}+$ is measured photometrically at $340 \mathrm{~nm}$ (maximum of $\mathrm{NADPH}$ ) using a microplate reader (Synergy 2 multi-mode reader, BioTek). The reduction of absorption is antiproportional to the GPx activity.

\section{Oxidized Low-Density Lipoprotein}

Oxidized LDL was determined by an ELISA kit from Mercodia (Uppsala, Sweden). During a 2-h incubation, the oxidized LDL binds to antioxidized LDL antibodies. After a washing step, the peroxidase-conjugated antihuman apolipoprotein B antibody is added. With 3,3',5,5'tetramethylbenzidin (TMB), the peroxidase forms the 3,3',5,5'-tetramethylbenzidin diimine. The amount of diimine is determined photometrically at $450 \mathrm{~nm}$.

\section{Statistics}

Results of DNA strand breaks and other parameters are reported as means, SD, and median. The Shapiro-Wilk test was used for the analysis of normal distribution. Differences of parameters between the study phases were analyzed with the onesided paired $t$ test (differences normally distributed) or with the one-sided paired Wilcoxon Signed Rank test (differences without normal distribution).

\section{Results}

\section{Study Design and Baseline Characteristics of Included Healthy Volunteers}

We performed an explorative human intervention study with ten healthy volunteers (non-smoking; BMI $25.8 \mathrm{~kg}$ / $\mathrm{m}^{2} \pm 4.2$; age 26.8 years \pm 4.7 ). Briefly, after a 2 -week polyphenol-reduced run-in phase, when volunteers consumed only $200 \mathrm{~mL}$ water in the morning and in the afternoon, for the following 4 weeks of intervention, they ingested an anthocyanin and micronutrient-rich food supplement (aronia+) in the morning $(25 \mathrm{~mL})$ and in the afternoon $(25 \mathrm{~mL})$ together with $200 \mathrm{~mL}$ water.

Body composition was determined after run-in and after 4 weeks of intervention. During the study period, the body composition of the ten volunteers did not change, as shown in Table 1.

To investigate the chemopreventive effect of the aronia+ supplementation on DNA strand breaks, blood samples were taken and analyzed by the comet assay. Additionally, to address the Nrf2/ARE-related signaling pathway, the effects on Nrf2 transcription and antioxidative enzymes (SOD, GPx, and CAT) as well as oxidized LDL (oxLDL) were determined in the blood samples together with standard blood lipids such as HDL, LDL, TC, and TG. 
Table 1 Body weight and body composition of the ten volunteers prior to and after 4-week consumption of aronia+

\begin{tabular}{lll}
\hline & Prior to intervention & After intervention \\
\hline Body weight (kg) & $85.3 \pm 15.4$ & $85.1 \pm 15.2$ \\
FFM (kg) & $66.0 \pm 7.8$ & $65.2 \pm 8.0$ \\
TBW (L) & $48.3 \pm 5.7$ & $47.7 \pm 5.8$ \\
FM (kg) & $19.3 \pm 8.6$ & $19.9 \pm 7.9$ \\
BMI $\left(\mathrm{kg} / \mathrm{m}^{2}\right)$ & $25.9 \pm 4.4$ & $25.8 \pm 4.4$ \\
\hline
\end{tabular}

Data are means and SD

$F F M$ fat free mass, $T B W$ total body water, $F M$ fat mass, $B M I$ body mass index

\section{Effects on DNA Strand Breaks}

After 4 weeks of intervention with aronia+, the total DNA strand breaks (comet assay after FPG treatment) were only marginally reduced in the blood samples of the ten volunteers. However, background DNA strand breaks (without FPG treatment) were more pronouncedly reduced $(p=0.06)$, as shown in Fig. 1. A closer look to the individual data of the volunteers showed that most of the volunteers responded to the supplement intake but depended on the initial tail intensity (TI\%) at the beginning of the intervention. The TI\% of all ten volunteers spread between 0.28 and 0.56 (data not shown). Interestingly, the volunteers with an initial TI of $>0.4 \%$ at day 1 responded more pronouncedly by trend to the supplement intake ( $p=0.06$, data not shown).

\section{Effects on Nrf2 Gene Expression and Activities of Nrf2/ARE-Related Enzymes}

Activation of Nrf2 gene expression was determined in lymphocytes. Blood samples' total RNA was isolated from peripheral blood lymphocytes (PBLs) before each stage of the

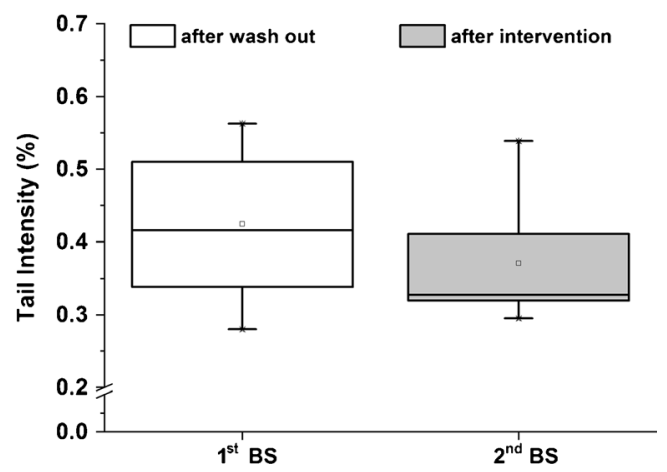

Fig. 1 Background DNA strand breaks (without FPG treatment) determined in white blood cells of ten volunteers at the beginning (1st $\mathrm{BS}$ ) and the end (2nd BS) of the aronia+ consumption over a period of 4 weeks. Data are expressed as TI\% showing means and SD. Squares represent mean values and horizontal lines within the boxes represent median values study. The gene transcript levels of Nrf2 were analyzed by RTqPCR. The Nrf2 gene expression (Fig. 2) was distinct (but not significant) and induced after the 4-week intervention period $(120 \% \pm 43 \%)$.

As a consequent step, Nrf2/ARE-related enzyme activities of SOD, CAT, and GPx in plasma samples of the volunteers were measured. Meanwhile, GPx and CAT activities were not affected (Table 2). SOD was significantly reduced after 4 weeks of supplement intake (from $100 \%(4.03 \mathrm{U} / \mathrm{mL}$ ) to $85.7(3.45 \mathrm{U} / \mathrm{mL}), p<0.05)$.

\section{Effects on Blood Lipids and Oxidized LDL Level}

Marginally decreases of plasma LDL and total cholesterol were observed with aronia+ after 4 weeks of intervention. The levels of HDL, TG, and oxidized LDL remained almost unchanged (Table 3).

\section{Discussion and Conclusion}

Previous human intervention studies have shown that the intake of red berries or red fruit juices has the potential to reduce background and total DNA strand breaks [7, 22, 23]. By way of example, daily consumption of $200 \mathrm{~mL}$ of anthocyanin-rich fruit juice by hemodialysis patients was associated with a significant decrease of total DNA damage and a significant increase of GSH levels in blood [23]. In another study with healthy volunteers who consumed an anthocyanin/ polyphenolic-rich fruit juice, decreased total DNA damage during the juice-uptake phase was observed [7]. Similar results were observed after consumption of other polyphenol sources, such as coffee [21, 24].

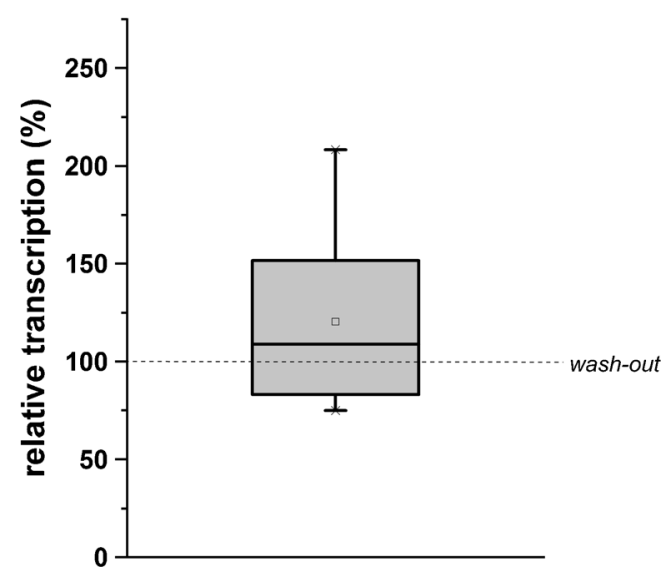

Fig. 2 Modulation of Nrf2 transcripts in human lymphocytes of ten volunteers after 4 weeks of intervention with aronia+. Data (box diagram) are normalized to housekeeping genes (GAPDH and $\beta$-actin) and are represented as relative transcription of individual levels of the participants after the wash-out period. Squares represent mean values and horizontal lines within the boxes represent median values 
Table 2 Antioxidative biomarkers in plasma of the ten volunteers prior to and after 4-week consumption of aronia+

\begin{tabular}{llc}
\hline Parameters & Prior to intervention & After intervention \\
\hline SOD $(\mathrm{U} / \mathrm{mL})$ & $4.03 \pm 0.65$ & $3.45 \pm 0.63^{*}$ \\
CAT $(\mathrm{nmol} / \mathrm{min} / \mathrm{mL})$ & $34.2 \pm 17.8$ & $28.5 \pm 16.5$ \\
GPx $(\mathrm{nmol} / \mathrm{min} / \mathrm{mL})$ & $78.0 \pm 23.6$ & $77.5 \pm 23.2$ \\
\hline
\end{tabular}

Data are means and SD

$S O D$ super oxide dismutase, $C A T$ catalase, $G P x$ glutathione peroxidase $* p<0.05$, significant differences in comparison to the wash-out period (prior to intervention)

This pilot study investigated, for the first time to our knowledge, effects of a polyphenol-rich but low-volume food supplement on potential protective effects on DNA strand breaks and antioxidative response. The studied formulation based on aronia juice but also containing micronutrients such as vitamins and trace elements zinc and selenium has previously shown to exhibit synergistic anti-inflammatory effects in vitro [19]. We therefore speculated that such synergistic effects might also result in measurable effects on DNA damage when comparably small amounts of red fruit juice were consumed. Indeed, tendencies towards a decrease were observed for total and, more pronounced, background DNA strand breaks after 4-week consumption of the food supplement. Furthermore, transcription levels of Nrf2 were elevated after the intervention; meanwhile, activities of Nrf2/ARErelated enzymes (GPx, CAT) were not affected or even decreased (SOD). Slight trends towards reduction in plasma LDL and total cholesterol levels were observed after the intervention, whereas HDL, triglycerides, and oxidized LDL were not changed. An induction of Nrf2 transcripts due to the intake of anthocyanin-rich fruits, fruit juices, or extracts was not reported in humans before. However, evidence exists from cell culture experiments and animal studies on the influence of polyphenolic compounds on the Nrf2 pathway; for instance, in Caco-2 cells, an increase in Nrf2 translocation, as well as an increase in Nrf2-related gene transcripts of NQO-1 and HO-1, was observed after application of 20 to $40 \mu \mathrm{M}$ cyanidin-3-glucoside [25]. Furthermore, in the retina cells of diabetic rats, anthocyanins from blueberries $(20,40$, or $80 \mathrm{mg} / \mathrm{kg}$ given orally for 12 weeks) led to an increased gene transcription of Nrf2 and HO-1 and an increase in nuclear location of Nrf2 and protein levels of HO-1 [26]. From the literature, it is also known that the intake of aronia juice $(300 \mathrm{~mL} / \mathrm{d})$ or aronia powder $(3 \mathrm{~g} / \mathrm{d})$ over 8 weeks reduces the inflammatory markers IL-10 and TNF- $\alpha$ in 38 volunteers, besides lowering effects on the blood pressure [27]. The observation of no effect on oxidized LDL levels in this study is in accordance with previous findings when 27 volunteers consumed an anthocyanin-rich juice $(330 \mathrm{~mL} / \mathrm{d})$ for 2 weeks [22]. Furthermore, similar results were observed when 25 former smokers were consuming an aronia extract $(500 \mathrm{mg} /$ day) for 12 weeks [28] or in a study with 56 male non-smoking volunteers consuming an anthocyanin-rich fruit juice for a period of 8 weeks (Bakuradze et al., unpublished).

Antioxidative enzyme levels were frequently reported from intervention studies with polyphenol-rich fruit juices. For instance, in a human intervention study, 30 female volunteers consumed an anthocyanin-rich red fruit juice $(330 \mathrm{~mL} / \mathrm{d})$. GPx was not modulated after 2 weeks of intervention, but SOD and CAT activities in the plasma of the volunteers were significantly increased [29]. In another study with 20 female volunteers, in contrast, no effects on GPx, CAT, or SOD activity in erythrocytes were observed after 2 weeks of cranberry juice intake $(750 \mathrm{~mL} / \mathrm{d})$ [30]. In the frame of another intervention study, membrane lipid peroxidation was reduced and the GPx activity in the erythrocytes was increased, meanwhile no impact on CAT and SOD activities was observed during a 4week daily consumption of a $100-\mathrm{mL}$ aronia juice formulation in 20 postmenopausal women with abdominal obesity [31]. In contrast, Broncel and coworkers reported on an increase in SOD and GPx and a decrease in CAT activity after a 2month intake of an aronia extract $(3 \times 100 \mathrm{mg} /$ day $)$ in patients suffering from a metabolic syndrome, besides a reduction in LDL and triglycerides [32].

Taking these observations together, it appears that before/ after comparisons of parameters of the antioxidative response should be considered with caution, since they might rather represent snapshots of the cellular status than the factual result of a longer-term intervention in healthy volunteers. We were
Table 3 Plasma lipids of the ten volunteers prior to and after $4-$ week consumption of aronia+

\begin{tabular}{llll}
\hline Plasma lipids & Prior to intervention & After intervention & Reference values \\
\hline TG $(\mathrm{mg} / \mathrm{dL})$ & $102 \pm 106$ & $94 \pm 71$ & $50-150$ \\
TC $(\mathrm{mg} / \mathrm{dL})$ & $206 \pm 42$ & $199 \pm 40$ & $50-220$ \\
$\mathrm{HDL}(\mathrm{mg} / \mathrm{dL})$ & $55 \pm 13$ & $54 \pm 13$ & $35-60$ \\
$\mathrm{LDL}(\mathrm{mg} / \mathrm{dL})$ & $124 \pm 37$ & $121 \pm 34$ & $<135$ \\
oxLDL $(\mathrm{U} / \mathrm{L})$ & $46.7 \pm 12.7$ & $46.9 \pm 13.6$ & $<117$ \\
\hline
\end{tabular}

Data are means and SD

$T G$ triglycerides, $T C$ total cholesterol, $H D L$ high-density lipoproteins, $L D L$ low-density lipoproteins, $o x L D L$ oxidized low-density lipoprotein 
aware of this potential influential factor when this study was planned; however, due to zinc being a cofactor of SOD and selenium of GPx, respectively, we envisaged that daily supplementation with these micronutrients might lead to a verifiable increase in the measured activity.

In contrast to conflicting results on antioxidative response enzymes, reports on the reduction of DNA strand breaks after consumption of polyphenol-rich extracts and juices are more consistent and propose that this parameter is more suitable for the determination of potentially protective effects.

In our study employing a polyphenol-rich but lowvolume food supplement, tendencies towards a decrease were observed for total and, more pronounced, background DNA strand breaks. These effects were not significant and thus must be considered preliminarily. A significant effect was also not expected; however, due to the pilot character of this first intervention study with the food supplement, a small number of healthy male volunteers $(n=10)$ only were employed. Besides a short intervention period, compared with several of the studies cited above, in particular, the lower anthocyanin/polyphenol dosage applied must be considered to be a cause for the rather small differences observed. Furthermore, and in contrast to some of the previously performed studies, this investigation was conducted with healthy volunteers. In particular, basal values of tail intensity (TI\%) were overall low in the population studied, such that achievable differences due to the intervention were already low. Post hoc analysis of data from volunteers exhibiting higher basal values for background DNA strand breaks (defined as $\mathrm{TI} \%>0.4, n=6$ ) indeed revealed more pronounced and almost significant effects $(p=0.06)$ on this parameter.

Another limitation of this study constitutes the uncontrolled design. Besides the risk of an overestimation of potentially (false) positive effects of the intervention for one thing, in fact, a control group taking a "placebo" of $200 \mathrm{~mL}$ water twice a day and being compliant to the polyphenol-reduced diet might yield more significant group differences due to an increase in tail intensity at the end of the observation period in the control group, as was reported from other investigations before [21].

As a conclusion, this explorative study yields first indications on protective effects on DNA strand breaks after intake of even small volumes of polyphenol-rich food supplements, but these observations must be confirmed in a follow-up study with a higher number of included volunteers.

Acknowledgements We thank Dr. Dorothea Schipp, Dr. Jean-Pierre Stockis, Sylvia Schmidt, Dirk Galan, Karlos Kespohl, and Selina Hemmer for their support. The authors gratefully acknowledge the gift of the FPG enzyme from Prof. A.R. Collins (Institute for Nutrition Research, University of Oslo, Norway).

\section{Compliance with Ethical Standards}

The study was approved by the ethics committee Rhineland-Palatinate, Mainz, Germany (no. 837.013.14 (9252-F)).

Conflict of Interest The trial was funded by Ursapharm Arzneimittel $\mathrm{GmbH}$, Saarbruecken, Germany. Peter Meiser is employed at Ursapharm Arzneimittel GmbH. The authors have declared that there is no further conflict of interest.

Human and Animal Rights and Informed Consent Written consent forms were signed and obtained from all volunteers. All volunteers were informed of the objectives of the study and consent was received for their participation.

Open Access This article is distributed under the terms of the Creative Commons Attribution 4.0 International License (http:// creativecommons.org/licenses/by/4.0/), which permits unrestricted use, distribution, and reproduction in any medium, provided you give appropriate credit to the original author(s) and the source, provide a link to the Creative Commons license, and indicate if changes were made.

\section{References}

1. Mittal M, Siddiqui MR, Tran K, Reddy SP, Malik AB. Reactive oxygen species in inflammation and tissue injury. Antioxid Redox Signal. 2014;20:1126-67. https://doi.org/10.1089/ars.2012.5149.

2. Rahman K. Studies on free radicals, antioxidants, and co-factors. Clin Interv Aging. 2007;2:219-36.

3. Xu Z, Du P, Meiser P, Jacob C. Proanthocyanidins: oligomeric structures with unique biochemical properties and great therapeutic promise. Nat Prod Commun. 2012;7:381-8.

4. Goodman GE, Thornquist MD, Balmes J, Cullen MR, Meyskens FL, Omenn GS, et al. The Beta-carotene and retinol efficacy trial: incidence of lung cancer and cardiovascular disease mortality during 6-year follow-up after stopping beta-carotene and retinol supplements. J Natl Cancer Inst. 2004;96:1743-50. https://doi.org/10. 1093/jnci/djh320.

5. Gomez-Cabrera M-C, Domenech E, Romagnoli M, Arduini A, Borras C, Pallardo FV, et al. Oral administration of vitamin C decreases muscle mitochondrial biogenesis and hampers traininginduced adaptations in endurance performance. Am J Clin Nutr. 2008;87:142-9. https://doi.org/10.1093/ajcn/87.1.142.

6. Ristow M, Zarse K, Oberbach A, Klöting N, Birringer M, Kiehntopf M, et al. Antioxidants prevent health-promoting effects of physical exercise in humans. Proc Natl Acad Sci U S A. 2009;106:8665-70. https://doi.org/10.1073/pnas.0903485106.

7. Weisel T, Baum M, Eisenbrand G, Dietrich H, Will F, Stockis J-P, et al. An anthocyanin/polyphenolic-rich fruit juice reduces oxidative DNA damage and increases glutathione level in healthy probands. Biotechnol J. 2006;1:388-97. https://doi.org/10.1002/biot. 200600004.

8. Kropat C, Mueller D, Boettler U, Zimmermann K, Heiss EH, Dirsch VM, et al. Modulation of Nrf2-dependent gene transcription by bilberry anthocyanins in vivo. Mol Nutr Food Res. 2013;57: 545-50. https://doi.org/10.1002/mnfr.201200504.

9. Hertog MG, Hollman PC, Katan MB, Kromhout D. Intake of potentially anticarcinogenic flavonoids and their determinants in adults in the Netherlands. Nutr Cancer. 1993;20:21-9. https://doi. org/10.1080/01635589309514267.

10. Kulling SE, Rawel HM. Chokeberry (Aronia melanocarpa) - a review on the characteristic components and potential health effects. 
Planta Med. 2008;74:1625-34. https://doi.org/10.1055/s-00281088306

11. Oszmiański J, Lachowicz S. Effect of the production of dried fruits and juice from chokeberry (Aronia melanocarpa L.) on the content and antioxidative activity of bioactive compounds. Molecules 2016. doi:https://doi.org/10.3390/molecules21081098.

12. Encyclopedia of human nutrition: Elsevier; 2013.

13. Carpenè E, Andreani G, Isani G. Metallothionein functions and structural characteristics. J Trace Elem Med Biol. 2007;21(Suppl 1):35-9. https://doi.org/10.1016/j.jtemb.2007.09.011.

14. Bellinger FP, Raman AV, Reeves MA, Berry MJ. Regulation and function of selenoproteins in human disease. Biochem J. 2009;422: 11-22. https://doi.org/10.1042/BJ20090219.

15. Holben DH, Smith AM. The diverse role of selenium within selenoproteins: a review. J Am Diet Assoc. 1999;99:836-43. https://doi.org/10.1016/S0002-8223(99)00198-4.

16. Bleys J, Navas-Acien A, Guallar E. Serum selenium levels and allcause, cancer, and cardiovascular mortality among US adults. Arch Intern Med. 2008;168:404-10. https://doi.org/10.1001/ archinternmed.2007.74.

17. Kipp AP, Strohm D, Brigelius-Flohé R, Schomburg L, Bechthold A, Leschik-Bonnet E, et al. Revised reference values for selenium intake. J Trace Elem Med Biol. 2015;32:195-9. https://doi.org/10. 1016/j.jtemb.2015.07.005.

18. Papp LV, Lu J, Holmgren A, Khanna KK. From selenium to selenoproteins: synthesis, identity, and their role in human health. Antioxid Redox Signal. 2007;9:775-806. https://doi.org/10.1089/ ars.2007.1528.

19. Appel K, Meiser P, Millán E, Collado JA, Rose T, Gras CC, et al. Chokeberry (Aronia melanocarpa (Michx.) Elliot) concentrate inhibits NF-KB and synergizes with selenium to inhibit the release of pro-inflammatory mediators in macrophages. Fitoterapia. 2015;105:73-82. https://doi.org/10.1016/j.fitote.2015.06.009.

20. Collins AR. The comet assay for DNA damage and repair: principles, applications, and limitations. Mol Biotechnol. 2004;26:24961. https://doi.org/10.1385/MB:26:3:249.

21. Bakuradze T, Lang R, Hofmann T, Eisenbrand G, Schipp D, Galan J, et al. Consumption of a dark roast coffee decreases the level of spontaneous DNA strand breaks: a randomized controlled trial. Eur J Nutr. 2015;54:149-56. https://doi.org/10.1007/s00394-014-0696-x.

22. Bub A, Watzl B, Blockhaus M, Briviba K, Liegibel U, Müller H, et al. Fruit juice consumption modulates antioxidative status, immune status and DNA damage. J Nutr Biochem. 2003;14:90-8.

23. Spormann TM, Albert FW, Rath T, Dietrich H, Will F, Stockis J-P, et al. Anthocyanin/polyphenolic-rich fruit juice reduces oxidative cell damage in an intervention study with patients on hemodialysis. Cancer Epidemiol Biomark Prev. 2008;17:3372-80. https://doi.org/ 10.1158/1055-9965.EPI-08-0364.

24. Bakuradze T, Lang R, Hofmann T, Schipp D, Galan J, Eisenbrand $\mathrm{G}$, et al. Coffee consumption rapidly reduces background DNA strand breaks in healthy humans: results of a short-term repeated uptake intervention study. Mol Nutr Food Res. 2016;60:682-6. https://doi.org/10.1002/mnfr.201500668.

25. Ferrari D, Speciale A, Cristani M, Fratantonio D, Molonia MS, Ranaldi G, et al. Cyanidin-3-O-glucoside inhibits NF-kB signalling in intestinal epithelial cells exposed to TNF- $\alpha$ and exerts protective effects via Nrf2 pathway activation. Toxicol Lett. 2016;264:51-8. https://doi.org/10.1016/j.toxlet.2016.10.014.

26. Song Y, Huang L, Yu J. Effects of blueberry anthocyanins on retinal oxidative stress and inflammation in diabetes through Nrf2/HO-1 signaling. J Neuroimmunol. 2016;301:1-6. https://doi.org/10.1016/ j.jneuroim.2016.11.001.

27. Loo B-M, Erlund I, Koli R, Puukka P, Hellström J, Wähälä K, et al. Consumption of chokeberry (Aronia mitschurinii) products modestly lowered blood pressure and reduced low-grade inflammation in patients with mildly elevated blood pressure. Nutr Res. 2016;36: 1222-30. https://doi.org/10.1016/j.nutres.2016.09.005.

28. Xie L, Vance T, Kim B, Lee SG, Caceres C, Wang Y, et al. Aronia berry polyphenol consumption reduces plasma total and lowdensity lipoprotein cholesterol in former smokers without lowering biomarkers of inflammation and oxidative stress: a randomized controlled trial. Nutr Res. 2017;37:67-77. https://doi.org/10.1016/ j.nutres.2016.12.007.

29. Kuntz S, Kunz C, Herrmann J, Borsch CH, Abel G, Fröhling B, et al. Anthocyanins from fruit juices improve the antioxidant status of healthy young female volunteers without affecting antiinflammatory parameters: results from the randomised, doubleblind, placebo-controlled, cross-over ANTHONIA (ANTHOcyanins in Nutrition Investigation Alliance) study. Br J Nutr. 2014;112:925-36. https://doi.org/10.1017/ S0007114514001482.

30. Duthie SJ, Jenkinson AM, Crozier A, Mullen W, Pirie L, Kyle J, et al. The effects of cranberry juice consumption on antioxidant status and biomarkers relating to heart disease and cancer in healthy human volunteers. Eur J Nutr. 2006;45:113-22. https://doi.org/10. 1007/s00394-005-0572-9.

31. Kardum N, Petrović-Oggiano G, Takic M, Glibetić N, Zec M, Debeljak-Martacic J, et al. Effects of glucomannan-enriched, aronia juice-based supplement on cellular antioxidant enzymes and membrane lipid status in subjects with abdominal obesity. Sci World J. 2014;2014:869250. https://doi.org/10.1155/2014/869250.

32. Broncel M, Kozirog M, Duchnowicz P, Koter-Michalak M, Sikora J, Chojnowska-Jezierska J. Aronia melanocarpa extract reduces blood pressure, serum endothelin, lipid, and oxidative stress marker levels in patients with metabolic syndrome. Med Sci Monit. 2010;16:CR28-34.

Publisher's Note Springer Nature remains neutral with regard to jurisdictional claims in published maps and institutional affiliations. 